\title{
Merkezsizleştirme Becerisini Değerlendirme: Yaşantılar Ölçeğinin Türkçe Formunun Psikometrik Özellikleri*
}

\section{Measuring Decentering: Psychometric properties of the Turkish Version of Experiences Questionnaire}

\author{
Fatma Zehra ÜNLÜ KAYNAKÇI ${ }^{* *}$
}

\begin{abstract}
$\ddot{O} \mathbf{z}$
Bu çalışmada, bilinçli farkındalığa dayalı yaklaşımların ortak unsuru olarak görülen merkezsizleştirme becerisini ölçen Yaşantılar Ölçeğinin (Fresco ve diğ., 2007) Türkçeye uyarlamasının yapılması amaçlanmıştır. Katlımcılar, Ankara'da bir devlet üniversitesinde okumakta olan 363 üniversite öğrencisinden (251 kadın, 112 erkek) oluşmaktadır. Yaşantılar Ölçeğinin tek faktörlü yapısını test etmek için Doğrulayıcı Faktör Analizi (DFA) yapılmıştır. DFA bulguları, ölçeğin tek faktörlü yapısının doğrulandığını göstermiş̧tir (Satorra-Bentler $\chi^{2} / d f=$ $3.05(p<.001), R M S E A=.07, N N F I=.93, C F I=.94$, SRMR $=.06, N F I=.92)$. Yaşantılar Ölçeğinin, merkezsizleştirme boyutunun Cronbach- $\alpha$ katsayısı .80 olarak bulunmuştur. Ayrıca ölçeğin ölçüt bağıntılı geçerliğini test etmek için Ruminasyon Ölçeği Kısa Formu (Treynor, Gonzealez ve Nolen-Hoeksama, 2003) ve Yaşantılar Ölçeği - Merkezsizleştirme arasındaki ilişki 620 üniversite öğrencisinin katılımıyla incelenmiştir. Ruminasyon ve merkezsizleştirme arasında negatif yönde anlamlı ilişki bulunmuştur. Sonuç olarak, üniversite öğrencilerinin katılımı ile gerçekleştirilen bu çalışmada Yaşantılar Ölçeği - Merkezsizleştirme Türkçe formunun geçerli ve güvenilir bir ölçme aracı olduğuna dair bulgular elde edilmiş̧ir. Elde edilen bulgular, alan yazın 1şığında tartışılmıştır.
\end{abstract}

Anahtar Kelimeler: Merkezsizleştirme, yaşantılar ölçeği, geçerlik, güvenirlik

\begin{abstract}
The aim of the current study was to adapt Experiences Questionnaire (EQ) (Fresco et.al, 2007) which measures decentering, a common element of all mindfulness-based therapies, into Turkish. The participants of the study were 363 undergraduate students ( 251 females, 112 males) enrolled at a state university in Ankara. Confirmatory Factor Analysis (CFA) was carried out to test the one factor structure of the Experiences Questionnaire. CFA results confirmed one factor structure of the questionnaire (Satorra-Bentler $\chi^{2} / d f=3.05(p<.001)$, RMSEA = .07 , NNFI $=.93, C F I=.94$, SRMR $=.06$ and NFI $=.92$ ). Cronbach alpha value for decentering factor of Experiences Questionnaire was found to be .80 . Furthermore, in order to test the criterion-related validity of the EQ-Decentering, the relationship between EQ- Decentering and the Short form of the Ruminative Response Scale (Treynor, Gonzealez, \& Nolen-Hoeksama, 2003) was investigated with the participation of 620 university students. Decentering was found to be significantly and negatively related to rumination. As a result, the current study conducted with the university students provided evidence for the reliability and validity of the Turkish form of EQ-Decentering. Findings were discussed in the light of the relevant literature.
\end{abstract}

Keywords: Decentering, experiences questionnaire, reliability, validity

\section{GíRiș}

Merkezsizleştirme, bireyin duygu ve düşünceleri ile olan ilişkisinde onlarla özdeşleşmesi ve onları tek bir gerçeklik olarak değerlendirmesi yerine duygu ve düşüncelerini zihninden geçen geçici olaylar

\footnotetext{
* Bu çalışmanın bir kısmı yazarın, Prof. Dr. Oya Yerin Güneri danışmanlığında 19 Haziran 2017 tarihinde tamamladığı "A model for psychological distress among university students: mindfulness, decentering, reframing, and indirect effect of emotion regulation difficulties" adlı doktora tezinden üretilmiştir. Ayrıca çalışma, 9-10 Nisan 2015 tarihlerinde Eskişehir'de düzenlenen VIII. Psikolojik Danışma ve Rehberlik Sempozyumun'da sözlü bildiri olarak sunulmuştur.

** Arş. Gör. Dr., Bülent Ecevit Üniversitesi, Eğitim Fakültesi, Ereğli-Zonguldak-Türkiye, e-posta: fzunlu@gmail.com, ORCID ID: orcid.org/0000-0002-9491-2750
} 
olarak gözlemlemesi becerisi olarak tanımlanmaktadır (Fresco ve diğ., 2007; Safran ve Segal, 1990). Mennin ve Fresco (2014), merkezsizleştirme kavramına açıklık getirirken duygu ve düşünceleri büyük bir göle benzetip merkezsizleştirmenin gölün içine atlamak yerine onun yanında oturup onu izlemek olarak açıklamıştır. Duygu ve düşünceleri uzaktan izleyebilmenin, onları daha objektif bir şekilde algılamaya (Fresco ve diğ., 2007; Safran ve Segal, 1990) ve olumsuz duygu ve düşüncelerin azalmasına yardımcı olduğu ifade edilmektedir (Segal, Williams ve Teasdale, 2002). Ayrıca merkezsizleştirme, Nolen-Hoeksema (1998) tarafından bireyin pasif ve tekrarlayan bir şekilde sıkıntılarının nedenleri ve sonuçları üzerine düşünmesi olarak tanımlanan ruminasyonun bir nevi zıttı olarak ele alınmış ve merkezsizleştirme becerisinin ruminasyona bir çeşit çözüm olduğu ifade edilmiştir (Segal, Williams ve Teasdale, 2012).

Merkezsizleştirme teriminin kökeni bilişsel yaklaşımdan gelmektedir (Beck, Rush, Shaw ve Emery, 1979). Ancak bilişsel yaklaşımlarda "üçüncü kuşak" veya "üçüncü dalga" olarak ifade edilen bilinçli farkındalık ve kabul temelli yaklaşımlarla merkezsizleştirme becerisinin psikolojik sağlık üzerindeki olumlu etkisi daha çok ön plana çıkmıştır (Fresco ve diğ., 2007). Özellikle, bilinçli farkındalık temelli yaklaşımlardan biri olan ve depresyona tekrar girmeyi önlemek için geliştirilmiş "Bilinçli Farkındalık Temelli Bilişsel Yaklaşımın” temelini oluşturmaktadır (Baer, Walsh ve Lykins, 2009; Segal ve diğ., 2012). Bununla birlikte tüm farkındalık temelli yaklaşımların ortak unsuru olarak görülmektedir (Baer ve Huss, 2008). Psikolojik danışma sürecinde ise merkezsizleştirme ile ilgili farklı bakış açıları bulunmaktadır. Bilişsel yaklaşım bağlamında, bu beceri işlevsel olmayan düşünceleri değiştirmek için bir yol olarak değerlendirilmektedir (Segal ve diğ., 2012). Başka bir deyişle merkezsizleştirme, işlevsel olmayan düşünceyi değiştirebilmenin ilk basamağıdır çünkü bu yaklaşımda danışanlar düşüncelerini merkezsîzleştirme bakış açısı ile değerlendirmeyi öğrenerek düşüncelerinin doğruluğu ve faydalılığı hakkında tartışabilirler (Hayes, 2004; Herbert ve Forman, 2011). Öte yandan, bilinçli farkındalık temelli yaklaşımlarda düşüncenin içeriğini değiştirmek gerekli görülmez veya danışmada çok sınırlı bir işlevinin olduğu düşünülür (Hayes, 2004; Sauer ve Baer, 2010). Bilinçli farkındalık temelli yaklaşımları geleneksel bilişsel davranışçı yaklaşımla bütünleştirip duygu bilimi ile entegre eden "Duygu Düzenleme Terapisi" ise merkezsizleştirmeyi duygu düzenleme becerisi olarak ele alır ve hem merkezsizleştime hem de düşünce içeriğinin değiştirilmesi bu yaklaşımın temel bileşenlerindendir (Mennin ve Fresco, 2014). Merkezsizleştirme kavramının psikolojik danışmada ele alınışı ile ilgili kuramlar arasında farklı bakış açıları olsa bile yaklaşımlar bu becerinin psikolojik danışmada öneminin altını çizmektedirler.

Bilinçli farkındalık temelli yaklaşımlarla birlikte araştırmalar hem bilinçli farkındalık hem de merkezsizleştirme'nin ruh sağlığı üzerindeki etkisine odaklanmakta ve bu becerilerin ruh sağlığını olumlu yönde etkilediğine dair sonuçlar elde edilmektedir. Çalışmalar özelikle merkezsizleştirmenin depresyon üzerindeki etkisine vurgu yapmaktadır (örn; Fresco, Segal, Buis ve Kennedy, 2007; McCracken, Gutierrez-Martinez ve Smyth, 2012). Ancak ruh sağlığı ile ilgili diğer değişkenler ile ilgili çalışmalar da merkezsizleştirme becerisinin ruh sağlığındaki önemini ortaya çıkarmaktadır. Örneğin; merkezsizleştirme becerisi arttıkça sosyal kaygı (Hayes-Skelton ve Graham, 2012), duygu düzenleme güçlükleri (Lafferty, 2013), alkol ile ilgili problemler (Pearson, Brown, Bravo ve Witkiewitz, 2014) ve psikolojik sıkıntının (Morgan, 2015) azaldığ belirtilmektedir.

Merkezsizleştirme becerisi bilinçli farkındalık bağlamında ele alınarak; ruh sağlığı ve bilinçli farkındalık arasındaki ilişkide merkezsizleştirmenin rolü incelenmiştir (Corcoran, Farb, Anderson ve Segal, 2010; Hayes-Skelton ve Graham, 2012). Shapiro, Carlson, Astin ve Freedman (2006) bilinçli farkındalı̆̆ın psikolojik sağlı üzerindeki etkisini merkezsizleştirme aracı rolü ile açıklayan bir farkındalık modeli sunmuştur. Buna göre, bilinçli farkındalık, merkezsizleştirme becerisinde önemli bir değişime neden olmakta ve bu değişim duygu-düşünce ve davranış esnekliği, öz düzenleme gibi mekanizmaları kolaylaştırmaktadır. Corcoran ve diğerleri (2010) da bilinçli farkındalık ve merkezsizleştirme ile ilgili bir model sunmuştur. $\mathrm{Bu}$ modele göre, bilinçli farkındalık duygu düzenlemeyi ve dikkat kapasitesini merkezsizleştirme aracı rolü ile artırmaktadır. Hölzel ve diğerleri (2011) tarafından geliştirilen diğer bir modele göre ise bilinçli farkındalık ile iyi oluş arasındaki ilişki; dikkat düzenleme, duygu düzenleme, beden farkındalığı ve kendilik üzerindeki algı değişimi aracı 
rolleri ile açıklanmaktadır. Kendilik üzerindeki algı değişimi ile merkezsizleştirme bakış açısı üzerinde durulmuştur.

Alan yazında, merkezsizleştirme becerisinin psikolojik sağlıkla doğrudan ilişkili olduğu ve aynı zamanda bilinçli farkındalık ve psikolojik sağlık arasındaki ilişkide kritik rolü vurgulanmaktadır. Ancak ulusal alan yazında bilinçli farkındalık ile ilgili çalışmalar (örn., Albayrak, 2015; Özyeşil, 2011; Ülev, 2014) hızla artmasına rağmen bilinçli farkındalığın oluşturduğu olumlu etkide anahtar role sahip olduğu öne sürülen merkezsizleştirme ile ilgili yayınlanmış bir çalışmaya rastlanmamıştır. Ülkemizde merkezsizleştirme becerisini ölçmeye yönelik bir ölçme aracının alana kazandırılmasının bu konu ile ilgili araştırmalar yapılmasına olumlu katkılar sağlayacağ 1 düşünülmektedir. Yaşantılar Ölçeği (Fresco ve diğ., 2007) ise merkezsizleştirme becerisini hem üniversite öğrencilerinde hem de klinik örneklemde ölçmek için kullanılan ve Almanya (Gecht ve diğ., 2014), Japonya (Kurihara, Hasegawa ve Nedate, 2011), İspanya (Soler ve diğ., 2014), Portekiz (Gregório, Pinto-Gouveia, Duarte ve Simoes, 2015), ve İran (Taherifar, Ferdowsi, Mootabi, Tehrani ve Fata, 2017) gibi farklı kültürlerde uyarlama çalışmaları yapılan bir ölçektir. Yapılan çalışmalar, ölçeğin merkezsizleştirme becerisini değerlendirmek için geçerli ve güvenilir olduğuna işaret etmektedir. Bu nedenle, Yaşantılar Ölçeği'nin Türkçeye uyarlama çalışmasının, bilinçli farkındalık temelli yaklaşımlarda ruh sağlığındaki kritik rolünün daha çok vurgulandığı merkezsizleştirme becerisini ölçmek için alana yeni bir ölçme aracı kazandırılması açısından önemli olduğu düşünülmektedir. Bu bağlamda, çalışmada Fresco ve diğerleri (2007) tarafından geliştirilen merkezsizleştirme becerisini ölçmek için kullanılan Yaşantılar Ölçeğinin Türkçeye uyarlanması amaçlanmaktadır.

\section{YÖNTEM}

Bu çalışma ölçek uyarlama çalışmasına uygun olarak tarama yöntemi ile gerçekleştirilmiştir. Tarama yöntemi belli bir popülasyonda belli bir değişkenin doğası veya sıklığı hakkında bilgi veren araştırma yöntemi olarak tanımlanmaktadır (Heppner, Wampold ve Kivlighan, 2008).

\section{Örneklem}

Çalışmaya, Ankara'da bir devlet üniversitesinde okumakta olan 394 üniversite öğrencisi katılmıştır. Çalışmanın örnekleminin belirlenmesinde uygun örnekleme (convenient sampling) yöntemi kullanılmıştır. Veri tarama işlemi sonucunda kayıp veri ve uç değerler nedeni ile örneklem sayısı 363 (251 kadın, 112 erkek) olarak belirlenmiştir. Katılımcıların yaş aralığı 18 ile 31 arasında değişmektedir ve yaş ortalaması 21.90 'dır $(s s=2.27)$. Katılımcıların akademik ortalamaları 0.50 ve 4.00 arasında değişiklik göstermiştir. Fakülte dağılımına bakıldığında 210'u (\%57.8) Eğitim Fakültesi, 83’ü (\%22.9) Fen Edebiyat Fakültesi, 41'i (\%11.3) Mühendislik Fakültesi, 22'si (\%6.1) İktisadi ve İdari Bilimler Fakültesi ve 7'si (\%1.9) Mimarlık Fakültesi öğrencileridir. Sınıf düzeyine göre katılımcıların dağılımı ise şu şekildedir: 53'ü (\%14.6) birinci sınıf, 88'i (\%24.2) ikinci sınıf, 97'si (\%26.7) üçüncü sınıf, 124'ü (\% 34.2) dördüncü sınıf öğrencisinden oluşmuş; 1 öğrenci (\%0.3) sınıfını belirtmemiştir. Çalışmanın ikinci kısmında, ölçeğin ölçüt geçerliğini test etmek için 429 kadın (\%69.2) ve 191 erkek (\%30.8) olmak üzere 620 lisans öğrencisinden veri toplanmıştır. Katılımcıların yaş aralığı 18 ve 30 arasında değişmektedir ve yaş ortalaması 21.88 'dir $(s s=1.68)$. Fakülte dağılımına bakıldığında, 367'sinin (\%59.2) Eğitim Fakültesi, 131'inin (\%21.1) Mühendislik Fakültesi, 72'sinin (\%11.6) Fen Edebiyat Fakültesi, 40’ının (\% 6.5) İktisadi ve İdari Bilimler Fakültesi ve 10'unun (\%1.6) Mimarlık Fakültesi öğrencileri olduğu görülmektedir. Sınıf düzeyinde ise 144'ü (\%23.2) birinci sınıf, 93’ü (\%15.0) ikinci sınıf, 177'si (\%28.5) üçüncü sınıf, 199’u (\% 32.1) dördüncü sınıf öğrencisinden oluşmuş; 7 öğrenci (\%1.1) sınıfını belirtmemiştir.

\section{Veri Toplama Araçları}

Yaşantılar Ölçeği (Fresco ve diğ., 2007) 
Yaşantılar ölçeği merkezsizleştirme ve ruminasyon olmak üzere iki alt ölçekten oluşmaktadır. Ölçek ilk oluşturulduğunda 14 madde merkezsizleştirme (örn; "Düşünce ve duygularımı kendimden ayrı tutabilirim") ve 6 madde ruminasyon (örn; "Başkalarının bana söyledikleri hakkında tekrar tekrar düşünürüm.") olmak üzere 20 maddeden oluşmaktadır. Merkezsizleştirme boyutundaki maddeler kişinin olumsuz deneyimlerine alışkanlıkla tepki göstermeme, kişinin kendini düşünceleri ile aynı görmeme ve öz şefkati ölçmeyi amaçlayan maddelerden oluşmaktadır. Ruminasyon ile ilgili maddeler ise tepki yanlılı̆̆ını kontrol etmek amacıyla kullanılmıştır. Fresco ve diğerleri (2007) tarafından yapılan analizler sonrasında iki faktörlü yapı doğrulanmamıştır ve sonrasında analiz sadece merkezsizleştirme maddelerini içeren tek faktörlü yap1 ile tekrar edilmiştir. Bu sonuçlara göre ise yaşantılar ölçeğinin 2, 5 ve 8. maddeleri teorik ve istatistiksel değerlendirmeler sonucunda ölçekten ç1kar1larak 11 maddelik (YÖ3, YÖ6, YÖ9, YÖ10, YÖ12, YÖ14, YÖ15, YÖ16, YÖ17, YÖ18, YÖ20) merkezsizleştirme alt boyutu geçerli ve güvenilir bulunmuştur. Sonuç olarak, Yaşantılar Ölçeği Merkezsizleştirme 11 maddeden oluşan 5'li likert tipinde bir ölçektir $(1=$ Hiçbir zaman; $5=$ Her zaman). Ölçekten alınabilecek en düşük puan 11 en yüksek puan 55'tir. Ölçekteki tüm maddeler olumlu yöndedir. Ölçekten alınan yüksek puanlar merkezsizleştirme becerisinin yüksek olduğunu göstermektedir. İç tutarlılık katsayısı Yaşantılar Ölçeği - Merkezsizleştirme için üniversite öğrencileri örnekleminde .83 ve klinik örneklemde .90 olarak bulunmuştur (Fresco ve diğ., 2007). Çalışma kapsamında araştırmacı tarafından ölçeğin Türkçeye uyarlama çalışması yapılmıştır. Yazarın talebi ile ölçeğin 20 maddelik orijinal hali Türkçeye çevrilmiştir.

\section{Ruminasyon Ölçeği Kısa Formu (Treynor ve dĭ̆., 2003)}

Ölçek ruminatif düşünceleri ölçmek için geliştirilmiştir. Saplantılı düşünme ve derin düşünme olmak üzere iki alt boyuttan oluşmaktadır. Saplantılı düşünce 5 madde ve derin düşünme 5 madde olmak üzere toplam 10 maddelik ve 4' lü likert tipi bir ölçektir (1 = Hiçbir zaman; 5 = Her zaman). Ölçek Türkçeye Erdur-Baker ve Bugay (2012) tarafından uyarlanmıştır. Orijinal formda Cronbach Alfa katsayısı derin düşünme .72 ve saplantılı düşünce .77 bulunmuştur.(Treynor ve diğ., 2003). Ölçeğin Türkçe formunda ise iç tutarlılık katsayısı tüm ölçek için .85, derin düşünme için .72 ve saplantılı düşünce için ise .77 olarak hesaplanmıştır (Baker ve Bugay, 2010).

\section{İşlem}

Ölçeğin uyarlama çalışması yapılmadan önce ölçeği geliştiren yazarlardan biri olan Fresco ile iletişime geçilerek ölçeğin Türkçeye uyarlama çalışması için izin alınmıştır. Sonrasında, ODTÜ İnsan Araştırmaları Etik Kurulundan izin alınarak ölçek uyarlama çalışması yapılmıştır. Ölçek uyarlama çalışması, Hambleton (2001) Uluslararası Test Komisyonu (International Test Commission; ITC) çeviri ve uyarlama rehberinde belirtilen beş aşama dikkate alınarak gerçekleştirilmiştir. Takip edilen aşamalar şunlardır: orijinal dilden hedef dile çeviri, uzmanlar tarafından ölçek maddeleri ile ilgili görüş alınması, bilişsel sorgulama yapılması ve hedeflenen örneklemde ölçeğin psikometrik özelliklerinin test edilmesidir. Bu doğrultuda ölçek İngilizce ve Türkçeyi iyi derecede bilen Rehberlik ve Psikolojik Danışma Bölümünde doktora yapan beş kişi tarafından bağımsız olarak Türkçeye çevrilmiştir. Çeviriler Rehberlik ve Psikolojik Danışma Bölümünde bir öğretim üyesi ve yine aynı bölümde doktora yapan bir kişi tarafından değerlendirilerek en doğru çevrilen maddeler seçilmiştir. Belirlenen ölçek maddeleri Eğitim Bilimlerinde öğretim üyesi olan iki kişiden görüş alınarak düzenlenmiştir. Ölçek izni kapsamında Fresco tarafından ölçeğin Türkçe formunun İngilizce' ye geri çevirisi istendiği için Rehberlik ve Psikolojik Danışma Bölümünde doktora yapan bir İngilizce öğretmeni tarafından ölçeğin İngilizceye geri çevirisi yapılmış ve yazardan ölçeğin uygunluğuna yönelik onay alınmıştır. Tüm bu aşamalar sonrasında bilişsel sorgulama kapsamında, eğitim fakültesinde okuyan 21 üniversite öğrencisine ölçek uygulanarak geri bildirim alınmıştır. Bu geri bildirimler şunlardır: Üstünlük belirteçleri içeren maddeler anlaşılır bulunmamıştır ve madde 17 "Düşüncelerimden ibaret olmadığımı görebiliyorum" maddesi çok soyut olarak değerlendirilmiştir. Geri bildirimler doğrultusunda üstünlük belirteçleri içeren maddeler ölçeğin tıpkı Almanca çevirisinde (Gecht ve diğ., 2014) olduğu gibi tekrar düzenlenmiştir. Örneğin; madde 3 "Kendimi olduğum gibi 
kabul etmede daha iyiyim", "Kendimi olduğum gibi kabul edebilirim" olarak değiştirilmiştir. Madde 17 "Düşüncelerimden ibaret olmadığımı görebiliyorum" ile ilgili olarak araştırmacı tarafindan öğrencilere bu maddeden ne anladıkları sorulmuştur. Açıklamalar ölçeğin kapsamıyla tutarlı olduğu için bu maddede herhangi bir değişiklik yapılmamıştır. Tüm bu aşamalardan sonra ölçeğin Türkçe formu oluşturulmuştur.

\section{Verilerin Analizi}

Ölçeğin geçerliğini test etmek için LISREL 8.80 programı kullanılarak Doğrulayıcı Faktör Analizi (DFA) yapılmış ve güvenirliğini belirlemek için Cronbach alfa iç tutarlık katsayısı hesaplanmıştır.

Gerekli analizlerin yapılmasından önce minimum ve maksimum değerlere bakılarak yanlış veri girişi olup olmadığı kontrol edilmiş ve kayıp değerler, uç değerler, doğrusallık ve normallik sayıltıları test edilmiştir. Kayıp değerler incelenmiş ve sadece 15 katılımcıda kayıp değer bulunduğu için liste bazında veri silme yöntemi kullanılarak bu kayıp değerler analizden çıkarılmıştır. Çalışmadaki 16 uç değer de analizden çıkarılmıştır. Dolayısıyla sonraki analizler 251'i kadın ve 112'si erkek olmak üzere 363 üniversite öğrencisi ile gerçekleştirilmiştir. Örneklem büyüklügünün uygunluğu LISREL 8.80 kullanılarak Hoelter's kritik $N$ (Critical N-CN) değeri ile 145.06 olarak hesaplanmıştır. Bu değer çalışmada kullanılan 363 birimlik örneklem büyüklüğünün doğrulayıcı faktör analizi için yeterli olduğunu göstermektedir. Normal dağılım varsayımına bakıldığında basıklık ve çarpıklık değerlerinin +3 ile -3 arasında olduğu görülmüştür (Tabachnick ve Fidell, 2007). Ancak çok değişkenli normal dağılım sayıltısı sağlanamadığı için Maksimum olasılık yerine Güçlü maksimum olasılık (Robust maximum likelihood) metodu kullanılmıştır.

Çalışmanın Doğrulayıcı Faktör Analizi sonuçlarının değerlendirilmesinde bazı uyum iyiliği indeksleri ve kabul edilebilir düzeyde uyumu işaret eden değerler dikkate alınmıştır. Bunlar; Ki-kare'nin serbestlik derecesine oranının $\left(\chi^{2} / s d\right)$ 5'den küçük olması (Wheaton ve diğ., 1977), NFI, NNFI ve CFI değerlerinin .95 'e yakın olması, SRMR değerinin .08 veya .08 'den küçük olması (Hu ve Bentler, 1999), RMSEA değerinin de .08'den küçük olması (Browne ve Cudeck, 1993)'dır.

\section{BULGULAR}

DFA sonuçlarına göre, Yaşantılar Ölçeği'nin iki faktörlü yapısı madde 2'nin anlamsız $t$ değerinden ve madde 4,11, 17 ve 8 'in bu sirayla düşük faktör yükü ve yüksek hata varyansı nedeni ile analizden çıkarılması ile doğrulanmıştır (Satorra-Bentler $\chi 2 / d f=2.76(\mathrm{p}<.001), C F I=.91, G F I=.93, S R M R=$ $0.06, R M S E A=0.07$ ve $N N F I=0.90)$. İç tutarlılık katsayıları, merkezsizleştirme alt ölçeği için .80 ancak ruminasyon alt ölçeği için .53 olarak bulunmuştur. Hair, Black, Babin ve Anderson (2010)'a göre güvenirlik katsayısının .70 üzerinde olması ölçeğin güvenilir olduğunu göstermektedir. Fraenkel ve Wallen (2006)'ya göre de güvenilir olmayan bir ölçeğin geçerli olması beklenmemelidir. Bu çalışmada da ruminasyon alt ölçeğinin yeterli güvenirliğe sahip olmamasından hareketle ve ölçeğin orijinal hali ve diğer uyarlama çalışmaları (örn; Fresco ve diğ., 2007; Soler ve diğ., 2014) dikkate alınarak sadece merkezsizleştirme maddeleri ile analiz tekrar edilmiştir.

Sadece 14 maddelik Yaşantılar Ölçeği-Merkezsizleştirme ölçeğine uygulanan doğrulayıcı faktör analizi sonucuna göre istatistiksel olarak anlamsız sonuç veren maddeler sirayla modelden çıkarılmıştır. İlk olarak YÖ2 anlamsız $t$ değerinden $(<.1 .96)$ dolayı, sonrasında sırayla YÖ17 ve YÖ8 düşük faktör yükü $(<.32$; Tabachnick ve Fidell, 2013) ve yüksek hata varyansı nedeni ile analizden çıkarılmıştır. Bu maddelerin çıkarılmasıyla gerçekleştirilen analiz sonrasında, Şekil 1'de de belirtildiği üzere ölçeğin tek faktörlü yapısının doğrulandığı görülmüştür (Satorra-Bentler $\chi^{2} / d f=3.05, R M S E A=$ .07). Ölçeğin CFI değeri .94, NNFI değeri .93, ve son olarak SRMR değeri .06 olarak elde edilmiştir (Tablo 1). Tablo 2' de analize ilişkin standartlaştırılmış yükler, $t$ - değeri ve $R^{2}$ sonuçları verilmiştir. Standartlaştırılmış yükler ve $R^{2}$ sonuçları merkezsizleștirmenin en çok madde YÖ14 (Kendime şefkatli davranabilirim) tarafindan açıklandığını göstermektedir. İç tutarlılık katsayısı ise Yaşantılar ÖlçeğiMerkezsizleştirme için .80 olarak hesaplanmıştır. 
Ünlü Kaynakçı, F., Z./ Merkezsizleştirme Becerisini Değerlendirme: Yaşantılar Ölçeğinin Türkçe Formunun Psikometrik Özellikleri

Tablo 1. Yaşantılar Ölçeği - Merkezsizleştirme için Uyum Ölçütleri

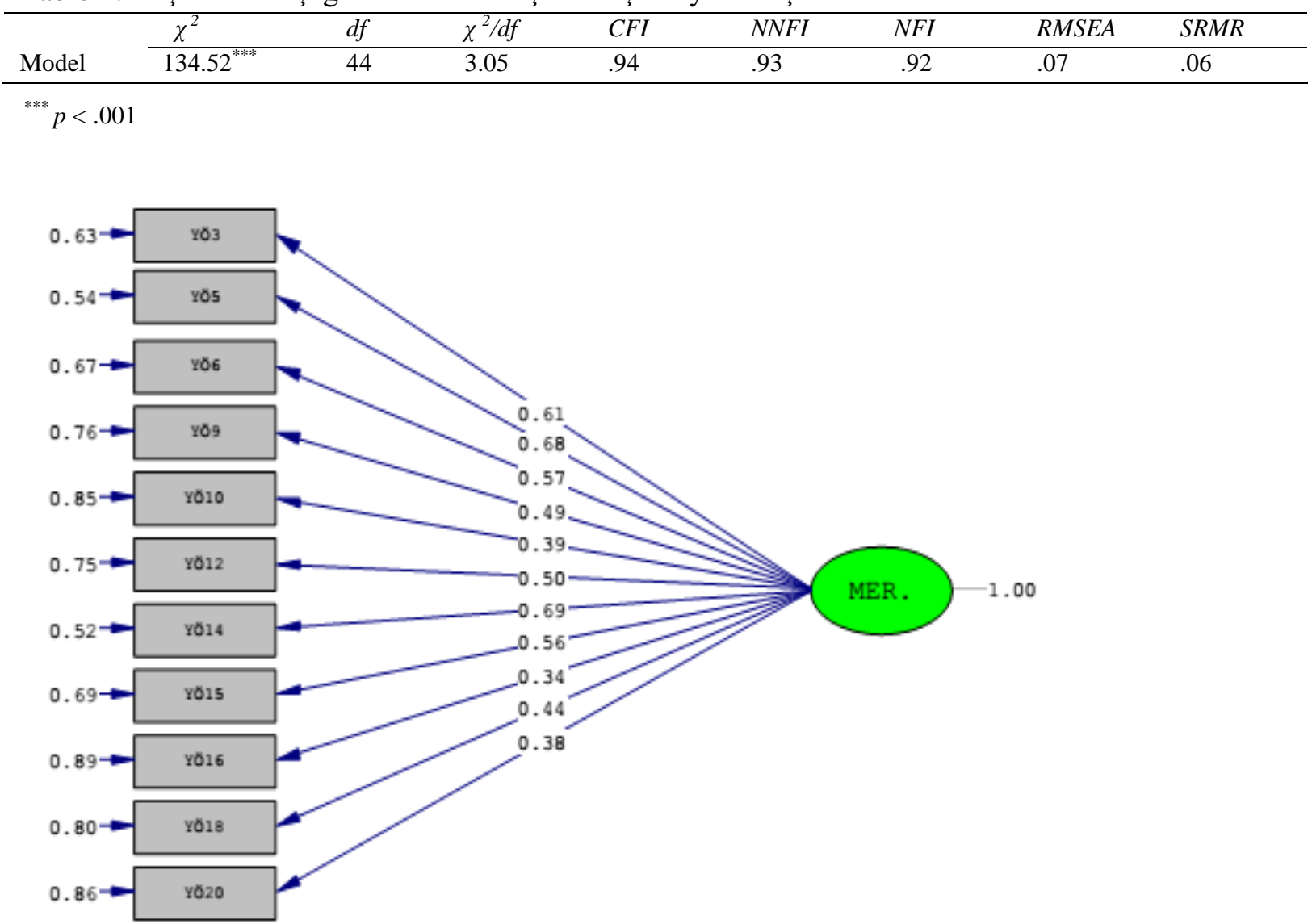

Chi-Square $=134.52, \mathrm{df}=44, \mathrm{P}$-value $=0.00000$, RMSEA=0.075

Şekil 1. Yaşantılar Ölçeği Merkezsizleştirme için Tek Faktörlü Model

Not. MER. $=$ Merkezsizleştirme

Tablo 2. Yaşantılar Ölçeği - Merkezsizleştirme için Doğrulayıcı Faktör Analizi Sonuçları (N=363)

\begin{tabular}{lcccc}
\hline Madde & $\begin{array}{c}\text { Standardize } \\
\text { Edilmiş Faktör } \\
\text { Yükleri }\end{array}$ & $\begin{array}{c}\text { Standardize } \\
\text { Edilmemiş Faktör } \\
\text { Yükleri }\end{array}$ & $t$ - değeri & $R^{2}$ \\
\hline YÖ3 & .61 & .54 & 12.82 & .37 \\
YÖ5 & .68 & .62 & 13.09 & .46 \\
YÖ6 & .57 & .52 & 10.07 & .33 \\
YÖ9 & .49 & .43 & 8.10 & .24 \\
YÖ10 & .39 & .37 & 6.11 & .15 \\
YÖ12 & .50 & .43 & 8.16 & .25 \\
YÖ14 & .69 & .61 & 13.73 & .48 \\
YÖ15 & .56 & .49 & 11.07 & .31 \\
YÖ16 & .34 & .27 & 6.07 & .11 \\
YÖ18 & .44 & .35 & 8.14 & .20 \\
YÖ20 & .38 & .29 & 7.19 & .14 \\
\hline
\end{tabular}

\section{Ölçüt Bağıntılı Geçerlik}

Teorik olarak ruminasyon merkezsizleştirme becerisinin bir nevi zıttı olarak değerlendirildiği için Yaşantılar Ölçeği - Merkezsizleştirme'nin ölçüt bağıntılı geçerliğini değerlendirmek üzere 620 
üniversite öğrencisine Ruminasyon Ölçeği Kısa Formu (Treynor ve diğ., 2003) ve Yaşantılar Ölçeği Merkezsizleştirme ölçekleri uygulamıştır. Ruminasyon ve Merkezsizleştirme arasındaki ilişki Pearson Çarpım Momentler Korelasyon Analizi ile incelenmiştir. Buna göre merkezsizleştirme ve ruminasyon arasında negatif yönde anlamlı bir ilişki bulunmuştur $(r=-.29, p<.001)$. Ayrıca, ruminasyon ölçeğinin alt boyutları olan saplantılı düşünme $(r=-.36, p<.001)$ ve derin düşünme $(r=-.16, p<.001)$ ile merkezsizleştirme arasında negatif yönde anlamlı ilişkiler olduğu görülmüsstür.

\section{SONUÇLAR ve TARTIŞMA}

$\mathrm{Bu}$ çalışmanın amacı, merkezsizleştirme becerisini değerlendirmek amacıyla Yaşantılar ölçeğini Türkçeye uyarlamaktır. Bu bağlamda, ölçeğin geçerlik ve güvenirliği bir grup üniversite öğrencisinde incelenmiştir. Yaşantılar Ölçeğinin iki faktörlü yapısından ruminasyon alt ölçeği güvenilir sonuçlar vermediği için tıpkı ölçeğin orijinal halinde olduğu gibi analizden çıkarılmıştır. Ruminasyon alt ölçeğinin analizden çıkarılmasının ardından Fresco ve diğerleri (2007) tarafından ölçeğin geliştirme aşamasında merkezsizleştirmeyi ölçtüğü varsayılan 14 madde ile analiz gerçekleştirilmiştir. DFA sonucuna göre, YÖ2 anlamsız $t$ değerinden, YÖ17 ve YÖ8 düşük faktör yükü nedeniyle ölçekten sırayla çıkarılmış ve Yaşantılar Ölçeği-Merkezsizleştirme'nin Türkçe formunda ölçeğin orijinalinde olduğu gibi 11 madde yer almıştır. Sonuç olarak ölçeğin tek faktörlü yapısı doğrulayıcı faktör analizi ile doğrulanmıştır. Bu çalışma bulgusu ile paralel olarak araştırmacıların ölçeğin merkezsizleştirmeyi tek faktörlü olarak kabul ettiği görülmektedir (Fresco ve diğ., 2007; Gregoria ve di ̌̆., 2015; Soler ve diğ., 2014).

Sonuçlara bakıldığında, ölçeğin orijinal hali oluşturulurken istatistiksel ve teorik olarak anlamsız bulunan madde 2 ve 8 bu çalışmada da benzer sonuçlar göstermiş ve o maddeler ölçekten çıkarılmıştır. Ölçeğin orijinal formu ile Türkçe formu arasında sadece iki maddede fark bulunmuştur. Bunlar; Madde 17 ("Aslında düşüncelerimden ibaret olmadığımı görebiliyorum.") çalışmanın örnekleminde anlamlı sonuçlar vermezken orijinal formda anlamlı sonuçlar vermiştir ve Madde 5 ("Bir şeyler yanlış gittiği zaman kendime nazik davranırım.") orijinal formda anlamsız sonuçlar verirken bu örneklemde anlamlı sonuçlar vermiştir. Madde 17 ile ilgili olarak, ölçek uyarlama aşamasında ölçeğin bir grup üniversite öğrencisine uygulanması sonrası alınan geribildirimlerde madde 17'nin açık ve anlaşı1ır olarak bulunmaması ile bağdaşır bir şekilde bu madde istatistiksel olarak da anlamlı sonuç vermemiştir.

Yaşantılar Ölçeği - Merkezsizleştirme'nin güvenirlik çalışması kapsamında, ölçeğin iç tutarlılık katsayısının Türkçe formu için yeterli düzeyde olduğu (.80) görülmektedir. Bu bulgunun ölçeğin Portekizce .82 (Gregório ve diğ., 2015), İngilizce .83 (Fresco ve diğerleri, 2007), İspanyolca 89 (Soler ve diğ., 2014), ve Farsça versiyonunda .77 (Taherif ve diğ., 2017) elde edilen verilerle hemen hemen benzer olduğunu göstermektedir.

Ölçeğin ölçüt bağıntılı geçerliği kapsamında, merkezsizleştirme ve ruminasyon arasındaki ilişki incelenmiştir. Elde edilen verilere göre merkezsizleştirme ve ruminasyon arasında negatif yönde anlamlı bir ilişki olduğu görülmüştür. Bu bulgu, merkezsizleştirme ile ruminasyon arasında negatif yönde ilişki olduğunu gösteren Fresco ve diğerleri (2007) ve Gregório ve diğerleri (2015) tarafindan gerçekleştirilen çalışmalar ile tutarlıdır.

Tüm bu sonuçlara bakıldığında, Yaşantılar Ölçeği -Merkezsizleştirme'nin çalışmanın örnekleminde psikometrik açıdan kabul edilebilir düzeyde güvenilir ve geçerli olduğu ve hem doğrulayıcı faktör analizi sonuçlarının hem de iç tutarlılık katsayısının orijinal çalışmada elde edilen bulgularla benzer olduğu görülmüştür. Yaşantılar Ölçeğinin üniversite örnekleminde Türkçeye uyarlamasının üniversite öğrencileri ile yapılacak ruh sağlığı çalışmalarına önemli katkılar sağlayacağı düşünülmektedir. Son olarak, çalışma kapsamında Türkçeye uyarlanan Yaşantılar Ölçeğinin, Farkındalık Temelli Bilişsel Terapi (Teasdale, Segal ve Williams, 1995) ve Duygu Düzenleme Terapisi (Mennin ve Fresco, 2009) gibi merkezsizleştirme becerisini temel ögelerden biri olarak alan terapilerin etkililiğini bu çalışmanın katılımcılarına benzer özellikteki kişilerde değerlendirmek için uygulayıcılar ve araştırmacılar tarafından kullanılabileceği düşünülmektedir. 
$\mathrm{Bu}$ önemli bulguların yanı sıra çalışma bazı sınırlılıklar barındırmaktadır. Çalışma uygun örnekleme yöntemi ile Ankara'daki tek bir devlet üniversitesinden veri toplanarak gerçekleştirilmiştir. Ayrıca örnekleminin büyük bir çoğunluğu kadın ve eğitim fakültesinde okuyan üniversite öğrencilerinden oluşmaktadır. Bu nedenle, üniversite öğrencilerini daha iyi temsil eden bir örneklem ile başlangıç niteliğindeki bu ölçek uyarlama çalışmasının yinelenmesinin faydalı olacağı düşünülmektedir. Özellikle depresyonun azalmasında etkili olduğu ifade edilen merkezsizleştirme becerisinin klinik örneklemde ölçülmesinin önemi vurgulanmaktadır. Bu nedenle, Yaşantılar Ölçeği - Merkezsizleştirme geçerlik ve güvenirlik çalışmasının Türkiye'de klinik örneklem ile de test edilmesi önerilmektedir. En son olarak bu çalışma tarama yöntemi kullanılarak gerçekleştirildiği ve katılımcılara anket uygulaması yapıldığı için katılımcıların kendilerine verilen veri toplama araçlarını içtenlikle ve nesnel olarak yanıtladıkları sayıltısına dayanmaktadır.

\section{KAYNAKÇA}

Albayrak. B. (2015).Üniversite öğrencilerinin bağlanma biçimleri, bilinçli farkındalık düzeyleri ve psikolojik belirtileri arasındaki iliş̧kiler (Yayımlanmamış Yüksek Lisans Tezi, Hasan Kalyoncu Üniversitesi). http://tez2.yok.gov.tr/ adresinden edinilmiş̧tir.

Baer, R. A., \& Huss, D. B. (2008). Mindfulness and acceptance-based therapy. In J. L. Lebow (Ed.), Twenty-first century psychotherapies: Contemporary approaches to theory and practice (pp. 123-166). United States of America: John Wiley \& Sons.

Baer, R. A., Walsh, E., \& Lykins, E. L. (2009). Assessment of mindfulness. In F. Didonna (Ed.), Clinical handbook of mindfulness (pp. 153-168). New York, NY: Springer.

Beck, A. T., Rush, A. J., Shaw, B. F., \& Emery, G. (1979). Cognitive therapy of depression. New York, NY: Guilford Press.

Browne, M. W., \& Cudeck, R. (1993). Alternative ways of assessing model fit. In K. A. Bollen \& J. S. Long (Ed.), Testing structural equation models (pp. 136-162). Newbury Park, CA: Sage.

Corcoran, K. M., Farb, N., Anderson, A., \& Segal, Z. V. (2010). Mindfulness and emotion regulation. In A. M. Kring \& D. M. Sloan (Eds.), Emotion regulation and psychopathology: A transdiagnostic approach to etiology and treatment (pp. 339-355). United States of America: Guilford Press.

Erdur-Baker, O., \& Bugay, A. (2012). The Turkish version of the Ruminative Response Scale: An examination of its reliability and validity. The International Journal of Educational and Psychological Assessment, 10(2), 1-16.

Fraenkel, J. R., \& Wallen, N. E. (2006). How to design and to evaluate research in education (3rd ed.). United State of America: Mc Graw Hill.

Fresco, D. M., Moore, M. T., van Dulmen, M. H., Segal, Z. V., Ma, S. H., Teasdale, J. D., \& Williams, J. M. G. (2007). Initial psychometric properties of the Experiences Questionnaire: Validation of a self-report measure of decentering. Behavior Therapy, 38(3), 234-246. http://doi.org/10.1016/j.beth.2006.08.003

Fresco, D. M., Segal, Z. V., Buis, T., \& Kennedy, S. (2007). Relationship of posttreatment decentering and cognitive reactivity to relapse in major depression. Journal of Consulting and Clinical Psychology, 75(3), 447. doi:10.1037/0022-006X.75.3.447

Gecht, J., Kessel, R., Mainz, V., Gauggel, S., Drueke, B., Scherer, A., \& Forkmann, T. (2014). Measuring decentering in self-reports: Psychometric properties of the Experiences Questionnaire in a German sample. Psychotherapy Research, 24(1), 67-79. http://dx.doi.org/10.10 80/10503307.2013.821635

Gregório, S., Pinto-Gouveia, J., Duarte, C., \& Simões, L. (2015). Expanding research on decentering as measured by the portuguese version of the experiences questionnaire. The Spanish Journal of Psychology, 18, 1-14. https://doi.org/10.1017/sjp.2015.18

Hair, J. F., Black, W. C., Babin, B. J., \& Anderson, R. E. (2010). Multivariate data analysis. (7th ed.). Upper Saddle River, NJ: Prentice Hall.

Hambleton, R. K. (2001). The next generation of the ITC test translation and adaptation guidelines. European Journal of Psychological Assessment, 17(3), 164-172. http://dx.doi.org/10.1027//1015-5759.17.3.164

Hayes, S. C. (2004). Acceptance and commitment therapy and the new behavior therapies: Mindfulness, acceptance, and relationship. In S. C. Hayes, V. M. Follette \& M. M. Linehan (Eds.), Mindfulness and acceptance: Expanding the cognitive-behavioral tradition (pp. 1-29). New York, NY: Guilford Press.

Hayes-Skelton, S., \& Graham, J. (2012). Decentering as a common link among mindfulness, cognitive reappraisal, and social anxiety. Behavioral and Cognitive Psychotherapy, 1(1), 1-12. https://doi.org/10.1017/S1352465812 000902 
Heppner, P. P., Kivlighan, D. M., \& Wampold, B. E. (2008). Research design in counseling. United State of America: Brooks/Cole

Herbert, J. D., \& Forman, E. M. (2011). The evolution of cognitive behavior therapy: The rise of psychological acceptance and mindfulness. In J. D. Herbert, \& E. M. Forman (Eds.), Acceptance and mindfulness in cognitive behavior therapy: Understanding and applying the new therapies (pp. 3-25). Hoboken, NJ: John Wiley \& Sons.

Hölzel, B. K., Lazar, S. W., Gard, T., Schuman-Olivier, Z., Vago, D. R., \& Ott, U. (2011). How does mindfulness meditation work? Proposing mechanisms of action from a conceptual and neural perspective. Perspectives on Psychological Science, 6(6), 537-559. doi:10.1177/1745691611419671

Hu, L., \& Bentler, P. M. (1999). Cutoff criteria for fit indexes in covariance structure analysis: Conventional criteria versus new alternatives. Structural Equation Modeling: A Multidisciplinary Journal, 6(1), 1-55. doi:10.1080/10705519909540118

Kurihara, A., Hasegawa, A., \& Nedate, K. (2011). Development of the Japanese version of the Experiences Questionnaire and examination of its reliability and validity. Japanese Journal of Personality, 19(2), 174-177. doi:10.4236/psych.2015.65059

Lafferty, M. (2013). Mediators of the relationship between mindfulness and alcohol use (Master thesis, Eastern Illinois University). Retrieved from http://thekeep.eiu.edu/cgi/viewcontent.cgi?article=2164 \&context $=$ theses

McCracken, L. M., Gutierrez-Martinez, O., \& Smyth, C. (2012). "Decentering" reflects psychological flexibility in people with chronic pain and correlates with their quality of functioning, Journal of Healthy Psychology, 32(7) 1-4. doi:10.1037/a0028093

Mennin, D. S., \& Fresco, D. M. (2009). Emotion regulation as an integrative framework for understanding and treating psychopathology. In A. M. Kring \& D. M. Sloan (Eds.), Emotion regulation and psychopathology: A transdiagnostic approach to etiology and treatment (pp. 356-379). New York, NY: Guilford Press.

Mennin, D. S., \& Fresco, D. M. (2014). Emotion regulation therapy. In J. J. Gross (Ed.), Handbook of emotion regulation (2nd ed., pp. 469-490). New York, NY: Guilford Press.

Morgan, L. P. (2015). In the face of adversity: Valued living and decentering as buffering factors in the relations among social disadvantage, psychological distress, drinking to cope and problem drinking (Doctoral dissertation). Available from Proquest Dissertation and Theses database. (UMI No. 3706474.)

Nolen-Hoeksema, S. (1998). The other end of the continuum: The costs of rumination. Psychological Inquiry, 9(3), 216-219. http://dx.doi.org/10.1207/s15327965pli0903_5

Özyeşil, Z. (2011). Üniversite öğrencilerinin öz-anlayış düzeylerinin bilinçli farkındalık kişilik özellikleri ve bazı değişkenler açısından incelenmesi (Doktara Tezi, Selçuk Üniversitesi). http://tez2.yok.gov.tr/ adresinden edinilmiştir.

Pearson, M. R., Brown, D. B., Bravo, A. J., \& Witkiewitz, K. (2015). Staying in the moment and finding purpose: The associations of trait mindfulness, decentering, and purpose in life with depressive symptoms, anxiety symptoms, and alcohol-related problems. Mindfulness, 6(3), 645-653. doi:10.1007/s12671-014-0300-8

Safran, J. D., \& Segal, Z. V. (1990). Cognitive therapy: An interpersonal process perspective. New York, NY: Basic.

Sauer, S., \& Baer, R. A. (2010). Mindfulness and decentering as mechanisms of change in mindfulness and acceptance-based interventions. In R. A. Baer (Ed.), Assessing mindfulness and acceptance processes in clients: Illuminating the theory and practice of change (pp. 25-50). United States of America: Context Press.

Segal, Z. V., Williams, J. M. G., \& Teasdale, J. D. (2002). Mindfulness-based cognitive therapy for depression: A new approach to relapse prevention. New York, NY: Guilford Press.

Segal, Z. V., Williams, J. M. G., \& Teasdale, J. D. (2012). Mindfulness-based cognitive therapy for depression. New York, NY: Guilford Press.

Shapiro, S. L., Carlson, L. E., Astin, J. A., \& Freedman, B. (2006). Mechanisms of mindfulness. Journal of Clinical Psychology, 62(3), 373-386. doi:10.1002/jclp.20237

Soler, J., Franquesa, A., Feliu-Soler, A., Cebolla, A., García-Campayo, J., Tejedor, R., ... Portella, M. J. (2014). Assessing decentering: Validation, psychometric properties, and clinical usefulness of the experiences questionnaire in a Spanish sample. Behavior Therapy, 45(6), 863-871. http://doi.org/10.1016/j.beth.2014 .05 .004

Tabachnick, B. G., \& Fidell, L. S. (2013). Using multivariate statistics (6th ed.). Boston: Pearson.

Taherifar, Z., Ferdowsi, S., Mootabi, M., Tehrani, M. A., \& Fata, L. (2017). Assessing "decentering": Validity, reliability and factor structure of experiences questionnaire in university students. Knowledge \& Research in Applied Psychology, 18(1), 46-56. http://journals.khuisf.ac.ir/jsr-p/article-1-2039-en.html 
Teasdale, J. D., Segal, Z., \& Williams, J. M. G. (1995). How does cognitive therapy prevent depressive relapse and why should attentional control (mindfulness) training help? Behavior Research and Therapy, 33(1), 25-39. https://doi.org/10.1016/0005-7967(94)E0011-7

Treynor, W., Gonzalez, R., \& Nolen-Hoeksema, S. (2003). Rumination reconsidered: A psychometric analysis. Cognitive Therapy and Research, 27(3), 247-259. https://doi.org/10.1023/A:1023910315561

Ülev, E. (2014). Üniversite öğrencilerinde bilinçli farkındalık düzeyi ile stresle başa çıkma tarzının depresyon, kaygl ve stres belirtileriyle ilişkisi (Yayımlanmamış Yüksek Lisans Tezi, Hacettepe Üniversitesi). http://tez2.yok.gov.tr/ adresinden edinilmiştir.

Wheaton, B., Muthen, B., Alwin, D. F., \& Summers, G. F. (1977). Assessing reliability and stability in panel models. Sociological Methodology, 8, 84-136.

\section{EXTENDED ABSTRACT}

\section{Introduction}

Decentering has been described as being able to observe or recognize thoughts and feelings as objective and temporary events in the mind rather than as absolute truths (Fresco et al., 2007). Decentering is a term that comes from cognitive therapy (Beck, Rush, Shaw, \& Emery, 1979), and it has gained greater importance with mindfulness and acceptance-based therapies (Fresco et al., 2007), and has been considered a common element of all mindfulness-based therapies (Baer \& Huss, 2008).

The role of decentering in several factors has been examined in a number of studies. For instance; studies have indicated that decentering is negatively correlated with depression (e.g., Fresco, Segal, Buis \& Kennedy, 2007), psychological distress (e.g., Morgan, 2015), social anxiety (e.g., HayesSkelton \& Graham, 2013), and emotion regulation difficulties (Lafferty, 2013). Moreover, decentering plays a key role in beneficial outcomes of mindfulness (e.g., Corcoran, Farb, Anderson \& Segal, 2010).

Recently, mindfulness has become a popular research topic in Turkey (e.g., Albayrak, 2015; Özyeşil, 2011; Ülev, 2014), but there is a lack of research on decentering. Experiences Questionnaire has been used to measure decentering with both undergraduate students and clinical sample (Fresco et al., 2007). Moreover, Experiences Questionnaire (EQ) has been conducted on different cultural groups such as German (Gecht et al., 2014), Japanese (Kurihara, Hasegawa, \& Nedate, 2011) and Spanish (Soler et al., 2014). Thus, the aim of the study is to adapt EQ into Turkish. Adapting the EQ into Turkish language can assist both practitioners and researchers to gain more insight about decentering in Turkey. The existing Turkish literature on decentering also can be advanced.

\section{Method}

In the present study, the Experience Questionnaire developed to measure both rumination and decentering was adapted into Turkish. The adapted scale included both EQ-Decentering (14 items) and EQ-Rumination (6 items) subscales.

Through the study, the permission to use EQ was obtained from Fresco who is one of the developers of the scale. The researcher also obtained approval from the Middle East Technical University Human Subjects Ethics Committee prior to data collection. Five bilingual persons translated the questionnaire into Turkish. Following the translation process, the best fitted translations of items were selected by the researcher. Secondly, three English language experts from School of Foreign Languages and Faculty of Education identified and worked on the inadequate expressions in translation of the items as well as any discrepancies between the original form and the translated one. Back translation was a required permission agreement offered by Fresco. Thus, back translation of the EQ was conducted by an English language instructor. The researcher applied the questionnaire to ten undergraduate students to get feedback on the comprehensibility of the EQ items.

The participants of this study were 394 undergraduate students from a state university in Ankara. After the data screening process, 31 cases were excluded from the data because of missing values (15 cases), 
and univariate and multivariate outliers (16 cases), and the sample size decreased to 363 undergraduate students. There were 251 females $(69 \%)$ and 112 males $(31 \%)$. The participants' ages ranged from 18 to 31 , and the mean age of the sample was $21.90(S D=2.27)$. In order to test the criterion-related validity of the EQ-Decentering, the Short form of the Ruminative Response Scale (Treynor, Gonzealez, \& Nolen-Hoeksama, 2003) was used, and the data were collected from 620 undergraduate students (429 females, 191 male).

\section{Results and Discussion}

Confirmatory factor analysis indicated an acceptable model fit for the two factor model, but EQRumination subscale had not an adequate reliability (.53). Therefore, EQ-Rumination factor was removed from the data file and the model was re-analyzed using only the decentering items. According to results, item 2 was eliminated because of non-significant $t$ value $(<.1 .96)$ as found in the original version of the scale, and item 17 and 8 (low standardized loading <.32; Tabacnick \& Fidell, 2013) were eliminated from the model. Therefore, confirmatory factor analysis indicated an acceptable model fit; Satorra-Bentler $\chi^{2} / d f=3.05(p<.001), C F I=.94, S R M R=0.06$ and $N F I=.92$, and Cronbach alpha for EQ-Decentering was calculated as .80.

The Turkish version of EQ-Decentering has strong evidence for construct validity and reliability. There were two differences between the Turkish version of EQ-Decentering and the original measure (Fresco et al., 2007). The first difference was EQ17 ("I can actually see that I am not my thoughts.") loaded significantly in the original measure, but in the Turkish version, EQ17 was removed from the model because of its low standardized loading. The second difference was EQ5 ("I am kinder to myself when things go wrong.") did not load significantly in the original measure; EQ5 loaded significantly in the present study. Except for these two differences, the questionnaire confirmed as having one-factor structure with acceptable fit indexes, and showed similar psychometric properties to the original measure (Fresco et al., 2007).

In order to test the criterion-related validity of the EQ-Decentering, the relationship between EQDecentering and the Short form of the Ruminative Response Scale (Treynor et al., 2003) was investigated with the participation of 620 university students. As expected, results revealed that there was a significant and negative relationship between decentering and rumination. This result was consistent with earlier studies (e.g., Fresco et al., 2007; Gregório et al., 2015).

In conclusion, the psychometric properties of the Experiences Questionnaire (EQ; Fresco et al., 2007) were examined in Turkey. Findings revealed its validity and reliability evidences in the current study conducted with undergraduate students. Measuring decentering accurately is important to evaluate the efficacy of theories such as Mindfulness-Based Cognitive Therapy (MBCT; Teasdale, Segal, \& Williams, 1995), and Emotion Regulation Therapy (ERT; Mennin \& Fresco, 2009) because decentering is one of the basic constructs of those theories (Mennin \& Fresco, 2014; Sauer \& Baer, 2010). Therefore, Experiences Questionnaire could be used to measure decentering by practitioners and researchers in Turkey. 